\title{
Octreotide - A Review of its Use in Treating Neuroendocrine Tumours
}

\author{
Frederico Costa ${ }^{1}$ and Brenda Gumz
}

1. Medical Oncologist, Oncology Centre, Hospital Sírio-Libanês, São Paulo, Brazil

\begin{abstract}
Neuroendocrine tumours (NETS) are a heterogeneous group of neoplasms whose incidence has dramatically increased in recent years. Octreotide is a somatostatin analogue used in the treatment of NETS, and its use in clinical trials has been associated with substantially increased survival. Although traditionally used for the relief of symptoms that result from release of peptides and neuroamines, there has been a growing body of evidence that suggest octreotide has antiproliferative effects. A phase III clinical study has demonstrated that the long-acting formulation (LAR), octreotide LAR, lengthens time to tumour progression in patients with well-differentiated metastatic midgut NETs, and that octreotide LAR is a treatment option for patients with metastatic midgut NETS, regardless of functional status. Furthermore, octreotide LAR has demonstrated clinical efficacy in different types of NETs. These data, along with emerging data on somatostatin analogs, may change the way doctors approach this patient population and reinforce the use of these drugs as a treatment option for patients with non-functioning tumours.
\end{abstract}

\section{Keywords}

Neuroendocrine tumours, octreotide, somatostatin analogues

Disclosure: The authors have no conflicts of interest to declare.

Acknowledgements: Editorial assistance was provided by Katrina Mountfort at Touch Medical Media.

Received: 16 October 2013 Accepted: 26 November 2013 Citation: European Endocrinology, 2014;10(1):70-4 DOI:10.17925/EE.2014.10.01.70

Correspondence: Frederico Costa, Oncology Centre, Hospital Sírio-Libanês, Adma Jafet Street, 91, São Paulo, SP, 0138-050, Brazil. E: Frederico.costa@hsl.org.br

Support: The publication of this article was supported by Novartis. The views and opinions expressed are those of the authors and not necessarily those of Novartis.

Neuroendocrine tumours (NETS) is a collective term for a diverse range of neoplasms that arise from cells that originate in the endocrine and nervous systems and share common morphological and immunohistochemical features, including the presence of secretory granules. These tumours can secrete a variety of neuropeptides, which may or may not cause characteristic hormonal symptoms (functioning or non-functioning NETS).

NETs have generally been considered rare; their incidence has been estimated at 2.5 to 5 per 100,000 people per year and prevalence of 35 per 100,0001 and may be higher if undiagnosed NETs are included. Autopsy studies have indicated that pancreatic NETs (pNETs) occur in $0.8 \%$ to $10 \%$ of patients undergoing a post-mortem examination. ${ }^{2}$ However, data from the largest US epidemiological database (SEER) indicate that the incidence of gastroenteropancreatic NETS (GEP-NETS ) is increasing dramatically in the US: a fivefold increase has been reported between 1973 and 2004 (see Figure 1). The incidence of GEP-NETs has risen steeply since 1992, and more than doubled since $1985 .{ }^{3}$ This is in contrast to the overall incidence of malignant neoplasms, which has remained relatively consistent since 1992. NETs of the lung, rectum and small intestine are currently the most frequently diagnosed NETs in the US and are also the three subgroups of NETS that have increased in incidence by the greatest margin from 1973 to 2004. ${ }^{3}$ The age-adjusted incidence of NETs of the small intestine and digestive system has increased by $460 \%$ and $720 \%$, respectively, over the past 30 years. ${ }^{4}$

NETs that secrete peptides and neuroamines can cause recognisable clinical syndromes, including carcinoid syndrome. ${ }^{4}$ However, due to the indolent nature of NETs, many patients are asymptomatic in the early stages, or present with only vague symptoms such as abdominal pain. ${ }^{4}$ As a result, NETS are frequently metastatic at the time of diagnosis: liver metastases are observed in $40 \%$ of patients who present with small intestinal and $60-70 \%$ of patients with pNETS., 3 Other factors influencing the presence of liver metastases include the primary tumour site, tumour stage, histological differentiation and proliferative activity (grading; G1-G3). Carcinoid syndrome is frequently associated with distant metastases, especially in the liver. The prognosis for NETS varies according to proliferative activity: median survival in distant metastatic disease was 33 months in patients with G1-G2 graded NETs, but only 5 months in patients with poorly differentiated carcinomas. ${ }^{3}$ The 5 -year survival rate was $35 \%$ in well to moderately differentiated (grade 1/2) NETs, but less than $5 \%$ in poorly differentiated grade 3 NETS. ${ }^{3}$

The first-line treatment strategy for NETs is surgery, but this is rarely curative, as most patients present at advanced stages of disease.,.5 Other treatment options include cytoreduction, radiological intervention (by embolisation and radiofrequency ablation) and chemotherapy. ${ }^{4}$ Surgical debulking can reduce the extent of hormone production and relieve symptoms, but owing to the long disease course, palliative care is important. Somatostatin analogues (SSAS), including octreotide and lanreotide, were introduced to control symptoms that result from release of peptides and neuroamines. Octreotide is the most studied SSA. This article aims to review the 25 years of clinical experience with octreotide in treatment of NETS. 


\section{Development and Clinical Uses of Octreotide}

Octreotide is a synthetic octapeptide SSA with more prolonged pharmacological actions than the endogenous hormone. Native somatostatin has a half-life of 2-3 minutes; octreotide has a halflife of 90-120 minutes when administered subcutaneously, and a pharmacodynamic action lasting up to 8-12 hours. ${ }^{6}$ Since octreotide resembles somatostatin in its physiological activities, it affects numerous pathways that may confer antiproliferative effects in NETS through inhibition of tumour angiogenesis and inhibition of secretion of growth factors. 7,8 Direct mechanisms by which octreotide achieves tumour regression include binding to somatostatin receptors sst ${ }_{2}$ and $\mathrm{sst}_{5}$, which are found in high density on tumour cells, ${ }^{9}$ and thereby inhibiting hormone secretion from the tumour, inducing apoptosis and cell cycle arrest, mainly through the regulation of phosphotyrosine phosphatase (PTP) and mitogen-activated protein (MAP) kinase. Binding to $\mathrm{sst}_{2}$ and $\mathrm{sst}_{5}$ receptors, octreotide blocks the effects of growth factor receptor stimulation and results in increased production of the cell cycle inhibitor p27.7 Binding to sst, receptors, SSAs affect the $\mathrm{PI}$ IK/AKt/mammalian target of rapamycin (MTOR) pathway and SHP1 signalling and may overlap with pathways used by the mTOR inhibitor, everolimus. ${ }^{10}$ Indirect effects include inhibition of angiogenesis and the release of secretory factors required for tumour growth, as well as modulation of the immune system (see Figure 2), and inhibition of insulin-like growth factor 1 (IGF-1) secretion. ${ }^{7,8,11}$

Octreotide is approved in the US and Europe for treatment of severe diarrhoea/flushing episodes associated with metastatic carcinoid tumours and profuse watery diarrhoea associated with vasoactive intestinal polypeptide (VIP)-secreting tumours. ${ }^{12,13}$ Octreotide is also approved in 42 countries for tumour control for advanced midgut NETs based on the Placebo-Controlled Prospective Randomized Study on the Antiproliferative Efficacy of Octreotide acetate LAR in Patients with Metastatic Neuroendocrine Midgut Tumours (PROMID) study. ${ }^{14}$ Additionally, treatment guidelines now recommend the use of octreotide as an antiproliferative agent in patients with functional and non-functional midgut NET, 15,16 based on results from the randomised phase III PROMID trial. ${ }^{17}$ Pooled data from more than 14 trials including almost 400 patients revealed that $71 \%$ of patients with GEP-NETs and carcinoid syndrome experience resolution or improvement of diarrhoea (range: 40-88\%) and flushing (range: 48-100\%) during treatment with octreotide. ${ }^{18-20}$ Octreotide can be used peri-operatively and may prevent carcinoid crisis, i.e. the immediate onset of debilitating and lifethreatening symptoms that are associated with carcinoid syndrome. ${ }^{21}$

Octreotide may also be used in asymptomatic patients at the time of diagnosis of metastatic disease. ${ }^{19}$ There is evidence that the impact of octreotide extends beyond symptom relief. A single-institution retrospective study of 90 consecutive patients with advanced GEP-NETS who received octreotide for carcinoid syndrome, found that a much greater percentage of patients treated with octreotide achieved 5-year survival from diagnosis compared with historical controls $(67 \%$ versus $18 \%$, respectively). ${ }^{22}$ Subsequent analysis of the SEER database found that survival in patients with metastatic NETs increased from 19 months (1973 to 1987) to 39 months (1988 to 2004) following the introduction of octreotide (see Figure 3). ${ }^{3}$ This increased survival was observed in patients with GEP-NETs and distant metastases; patients with localised and regional disease did not exhibit significantly extended survival time. A possible explanation for this improvement may be that not only does octreotide achieve control of the symptoms of carcinoid syndrome but also has a potential antiproliferative effect, which could alter the natura
Figure 1: SEER Data Showing the Increased Incidence of Neuroendocrine Tumours

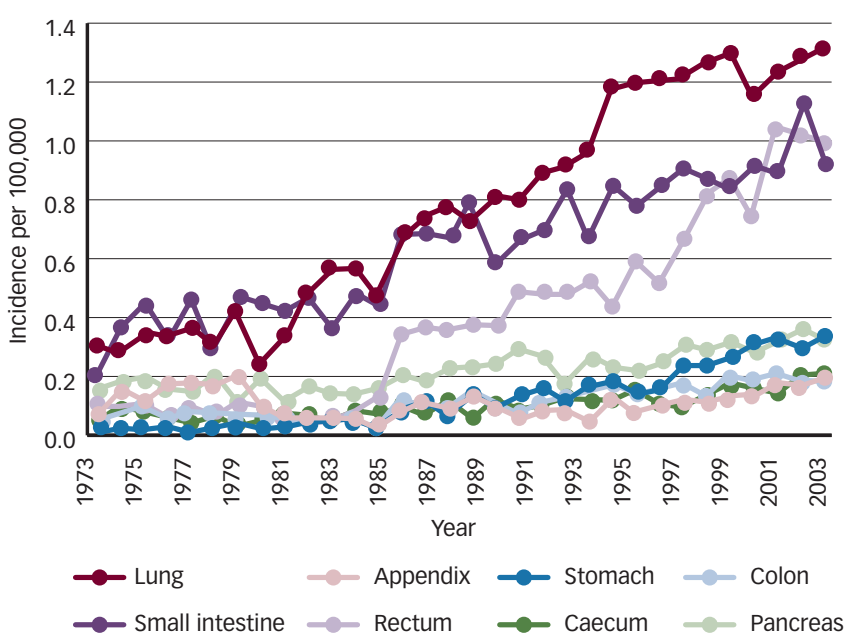

Source: Yao et al., 2008. ${ }^{3}$

\section{Figure 2: Direct and Indirect Antiproliferative Effects of Octreotide}

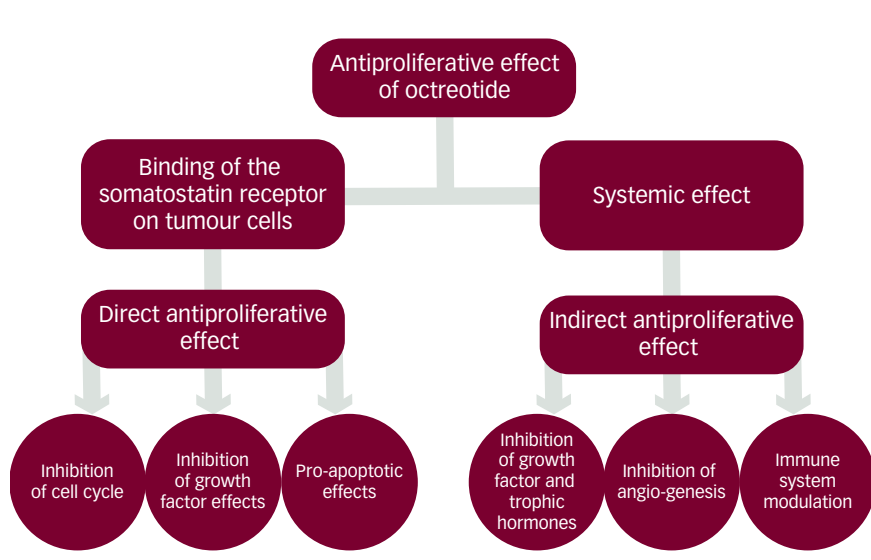

Source: Susini and Buscali, $2006 .^{8}$

\section{Figure 3: Improved Survival Following the Introduction of Octreotide Acetate Long-acting Release}

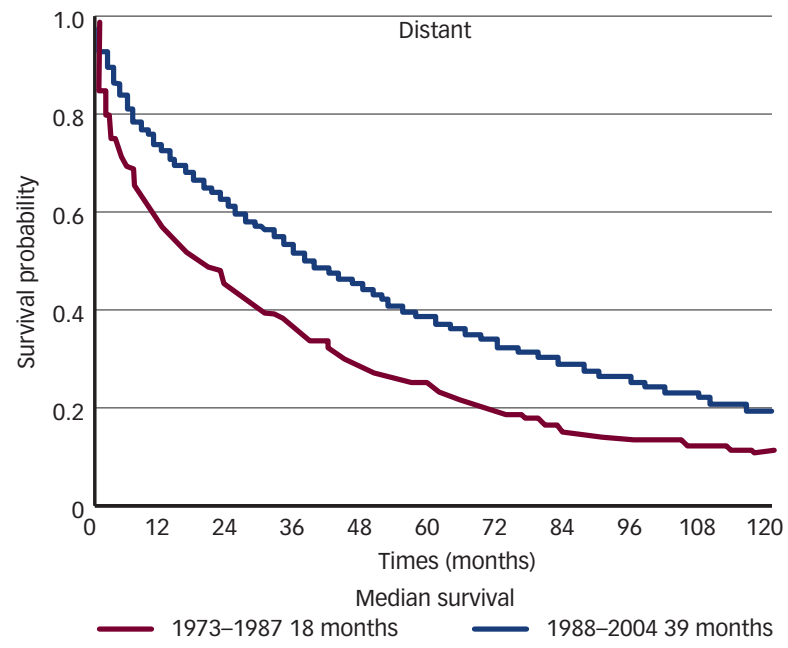

Data taken from an analysis of 35,825 cases of gastroenteropancreatic-neuroendocrine tumours identified in the SEER registries. Source: Yao et al., 2008. ${ }^{3}$ 


\section{Table 1: Summary of Clinical Evidence Suggesting Antitumour Activity of Octreotide Monotherapy in Patients with Progressive Gastroenteropancreatic-Neuroendocrine Tumours}

\begin{tabular}{|c|c|c|c|}
\hline Study Type & Regimen & Results & Reference \\
\hline $\begin{array}{l}\text { Phase II trial, } n=34 \text {, patients with advanced functioning } \\
(n=21) \text { and not functioning }(n=13) \text { carcinoid or islet cell NETs }\end{array}$ & Octreotide SC $250 \mu g$ TID & $\begin{array}{l}\text { SD in } 50 \% \text { of patients for median } \\
5 \text { months (range } 2-27 \text { months) }\end{array}$ & 45 \\
\hline $\begin{array}{l}\text { Phase II trial, } \mathrm{n}=103 \text {, metastatic GEP-NETs. } 64 \text { functioning } \\
\text { and } 39 \text { non-functioning }\end{array}$ & Octreotide SC $200 \mu \mathrm{g}$ TID & $\begin{array}{l}\text { SD in } 36.5 \% \text { of patients for median } \\
18 \text { months (range } 3 \text { to }>42 \text { months) }\end{array}$ & 46 \\
\hline $\begin{array}{l}\text { Phase II trial, } \mathrm{n}=58, \text { patients with histological evidence of } \\
\text { carcinoid or other NETs }\end{array}$ & $\begin{array}{l}\text { Octreotide SC } 500 \mu g \text { TID }(n=23) \\
\text { versus octreotide SC 1,000 } \mu \text { g TID }(n=35)\end{array}$ & $\begin{array}{l}\text { SD in } 47 \% \text { for at least } 6 \text { months and } \\
\text { at least } 1 \text { year in } 22 \% \text {; PR in } 3 \%\end{array}$ & 47 \\
\hline $\begin{array}{l}\text { Prospective study, } n=35,18 \text { functional, progressive } \\
\text { metastatic NETs }\end{array}$ & $\begin{array}{l}\text { Octreotide acetate LAR SC } 100 \mu g \text { three times } \\
\text { daily (max } 100 \mu g \text { times/day ) or lanreotide } \\
30 \text { mg every } 14 \text { days (max } 30 \text { mg/10 days) }\end{array}$ & $\begin{array}{l}\text { SD in } 57 \% \text { for median } 7 \text { months. } \\
\text { PR in } 3 \%\end{array}$ & 48 \\
\hline Phase II trial, $\mathrm{n}=32$, progressive, metastatic, pNETs & $\begin{array}{l}\text { Octreotide acetate LAR } 30 \text { mg/28 days }(n=20) \\
\text { versus lanreotide SR } 60 \text { mg/28 days }(n=11)\end{array}$ & $\begin{array}{l}\text { SD in } 45.2 \% \text { of patients } \\
\text { for } 6-60 \text { months }\end{array}$ & 29 \\
\hline Prospective study, $n=15$, gastric carcinoid tumours type 1 & $\begin{array}{l}\text { Octreotide acetate LAR } 20-30 \mathrm{mg} / \mathrm{month} \\
(\mathrm{n}=14) \text { or lanreotide } 90 \mathrm{mg} / \mathrm{monthly}(\mathrm{n}=1)\end{array}$ & $\begin{array}{l}\text { At } 1 \text { year, } 73 \% \text { observed complete } \\
\text { disappearance of tumours; } 20 \% \text { had } \\
\text { a significant decrease in the number } \\
\text { and size of tumour }\end{array}$ & 11 \\
\hline $\begin{array}{l}\text { Prospective study, } n=15 \text {, advanced progressive metastatic } \\
\text { gastrinoma characterised by Zollinger-Ellison syndrome } \\
\text { and liver metastases }\end{array}$ & Octreotide acetate LAR 30 mg/28 days & $\begin{array}{l}\text { At } 3 \text { months, SD in } 47 \% \text {. Mean } \\
\text { duration of response was } 25.0 \pm 6.1 \\
\text { months (range } 5.5-54.1 \text { months) }\end{array}$ & 32 \\
\hline $\begin{array}{l}\text { Prospective phase IV study ( } \mathrm{n}=21) \text {, well-differentiated, } \\
\text { non-functioning advanced pNET }\end{array}$ & Octreotide acetate LAR 30 mg/28 days & SD in $35 \%$ & 49 \\
\hline $\begin{array}{l}\text { Phase III study ( } n=19) \text {, progressive NETs of the pancreas } \\
\text { and bronchial tract }\end{array}$ & $\begin{array}{l}\text { Octreotide acetate LAR } 30 \text { mg/28 days versus } \\
\text { chemotherapy (streptozotocin + 5-fluorouracil) }\end{array}$ & $\mathrm{SD}$ in $26 \%, \mathrm{PR}$ in $11 \%$ & 31 \\
\hline $\begin{array}{l}\text { Phase III study (PROMID), } n=85 \text {, well-differentiated } \\
\text { metastatic NETs of the midgut }\end{array}$ & $\begin{array}{l}\text { Octreotide acetate LAR } 30 \mathrm{mg} \text { / } \\
28 \text { days versus placebo }\end{array}$ & $\begin{array}{l}\text { At } 6 \text { months, SD in } 66.7 \% \\
\text { versus } 37.2 \% \text { placebo; PR in } 2 \%\end{array}$ & 17 \\
\hline $\begin{array}{l}\text { Phase III multinational, randomised, double blind trial } \\
\text { RADIANT-2 }\end{array}$ & $\begin{array}{l}\text { Everolimus } 10 \text { mg/day + octreotide acetate } \\
\text { LAR } 30 \text { mg/28 days versus placebo + } \\
\text { octreotide acetate LAR } 30 \text { mg/28 days }\end{array}$ & $\begin{array}{l}\text { SD } 84 \% \text { versus } 81 \% \text { in placebo; } \\
\text { PR in } 1 \%\end{array}$ & 28 \\
\hline
\end{tabular}

GEP-NETS = gastroenteropancreatic-neuroendocrine tumours; $L A R=$ long-acting release; $p N E T S=$ pancreatic NETS; $P R=p a r t i a l$ response; $S C=$ subcutaneous; $S D=$ stable disease $S R=$ short release $; T I D=$ three times daily.

history of NETS. Potential lethal consequences associated with carcinoid crisis, such as severe flushing, diarrhoea, valvular heart disease and haemodynamic instability, are now rare occurrences. Complications due to tumour progression tend to occur later in the disease course. ${ }^{3}$

The development of the long-acting release (LAR) formulation of octreotide in 1997 (Sandostatin ${ }^{\circledR}$ LAR, Novartis) further improved the clinical utility of this drug. Octreotide acetate LAR (octreotide LAR) is a formulation in which octreotide acetate is encapsulated in microspheres of a slowly dissolving polymer, providing a predictable pharmacokinetic profile and steady-state kinetics when injected intramuscularly once every 28 days. ${ }^{23}$ Octreotide LAR retains the pharmacological characteristics of the previous subcutaneously (SC) administered formulation of octreotide, and reaches steady-state concentrations within three injections. ${ }^{24} \mathrm{~A}$ retrospective study compared survival in 145 patients with carcinoid syndrome who received octreotide LAR between 1996 and 2004 to 90 patients who received SC octreotide between 1986 and 1995. Patients who received treatment with octreotide LAR had a $66 \%$ (range $46-82 \%$ ) lower risk of death than patients who had received SC octreotide $(p<0.0001) .{ }^{25}$

The benefits of octreotide LAR therapy are clearly established. However, recently, the effect of octreotide LAR in controlling tumour growth has been demonstrated..$^{1726-28}$ Multiple uncontrolled studies showed that administration of octreotide is associated with tumour stabilisation in patients with progressive NETs. ${ }^{11,29-32}$ However, these early studies failed to comprehensively define the role of octreotide in controlling tumour growth, since studies were small, single-centre and not placebo controlled. Furthermore, patients were not treatment naïve and data from GEP-NETS of different origin, (foregut, midgut and hindgut) were analysed together. The observed growth-inhibiting effects of SSAs were not identical in these subgroups and, because of the small numbers involved, firm conclusions could not be drawn. A randomised, double blind, placebo-controlled trial enrolling a homogenous group of patients was necessary to provide definitive evidence of an antiproliferative effect of octreotide LAR.

\section{Clinical Data Demonstrating the Antiproliferative Effect of Octreotide}

There is a long history of evidence for the antiproliferative effects of octreotide. Evidence from preclinical cancer models showed that octreotide LAR had antitumour activity. ${ }^{33}$ In prospective studies, octreotide LAR has exhibited an antiproliferative effect in the following types of NET: entero-pancreatic, well-differentiated endocrine carcinomas, ${ }^{29}$ gastric carcinoid tumours, ${ }^{11}$ metastatic or locally advanced, well-differentiated NETS, ${ }^{30}$ progressive NETs of the pancreas and bronchial tract ${ }^{31}$ and advanced, progressive metastatic gastrinoma characterised by ZollingerEllison syndrome (ZES) and liver metastases. ${ }^{32}$ Table 1 summarises clinical studies that have demonstrated the antiproliferative effect of short- and long-acting formulations of octreotide.

The most robust data have been provided by the phase III PROMID trial. In this study, newly diagnosed and treatment-naïve patients were randomised to placebo or octreotide LAR administered intramuscularly every 28 days for 18 months or until tumour progression or death. ${ }^{17}$ To avoid a heterogeneous patient population with GEP-NETs of different origin and biological behaviour, only patients with well-differentiated metastatic or locally inoperable midgut tumours were included. Midgut NETs represent the largest subgroup of NETs, and by targeting 
these patients, the PROMID study therefore involved the largest homogeneous NET patient population. Enrolment criteria permitted patients to have either a functioning (patients that could tolerate symptoms with loperamide and clinical support) or non-functioning tumour: those with symptoms of carcinoid syndrome and increased urinary 5-hydroxyindole acetic acid (5-HIAA) were classified as having a functioning tumour. Hepatic tumour load (HL) was quantified by computed tomography (CT) or magnetic resonance imaging (MRI).

Results from 85 patients showed that the median time to tumour progression (TTP) in the octreotide LAR and placebo groups was 14.3 and 6 months, respectively (hazard ratio $[\mathrm{HR}]=0.34 ; 95 \%$ confidence interval $[\mathrm{Cl}]$ 0.20-0.59; $\mathrm{p}=0.000072$ ) (see Figure 4). ${ }^{17}$ After 6 months of treatment, stable disease was observed in $66.7 \%$ of patients in the octreotide LAR group and $37.2 \%$ of patients in the placebo group. The HR for overall survival (OS) was 0.81 (95\% Cl 0.30-2.18). Most patients in the PROMID study benefited from octreotide LAR $30 \mathrm{mg}$ therapy, although those patients with non-functioning NETs experienced the most benefit. Safety data were consistent with those seen in previous studies of octreotide LAR. While the proportion of patients with extended TTP was highest in those with low HL ( $\leq 10 \%)$ versus placebo, subgroup analysis of data from patients with $\mathrm{HL}>10 \%(n=21)$ revealed that octreotide LAR extends TTP regardless of $\mathrm{HL}^{27}$

The beneficial effects of octreotide LAR may also include OS: patients from the PROMID trial were followed at least once a year until January 2013. In the $\mathrm{HL}<10 \%$ subgroup, median OS was not reached (octreotide $\mathrm{LAR}$ ) versus 80.5 months (placebo) $(H R=0.56,95 \% \mathrm{Cl} 0.25-1.23 ; \mathrm{p}=0.14)$. In the $\mathrm{HL}>10 \%$ subgroup, OS was 35 versus 84 months (HR=2.18, $95 \% \mathrm{Cl}$ 0.75-6.33; $\mathrm{p}=0.14)$. The estimated HR of 0.56 in octreotide LAR-treated patients in the subgroup with low $\mathrm{HL}$ indicated a risk reduction of $44 \%$ compared with placebo. ${ }^{26}$ This benefit was confirmed after 84.7 months of median follow-up. ${ }^{26}$ Also, the recently presented phase III, randomised, double-blind, placebo-controlled Lanreotide Antiproliferative Response in patients with GEP-NET (CLARINET) study with 204 NET patients enrolled, demonstrated the antiproliferative effects of another SSA - lanreotide. ${ }^{34}$

The RAD001 in Advanced Neuroendocrine Tumors, Second Trial (RADIANT-2) was a multinational, randomised, double-blind phase III trial with 429 patients with functioning NET that aimed to evaluate the combination of everolimus + octreotide versus placebo + octreotide. ${ }^{28}$ Patients included in the study had functioning NETs, low or intermediate grade, with inoperable or locally advanced disease. All patients had radiological documentation of progression within 12 months of randomisation. About $50 \%$ of the patients had primary tumours from the small intestine and $80 \%$ of patients had well-differentiated tumours. About $80 \%$ of patients had used SSAs for about 2.5 years; $78 \%$ of patients had used octreotide LAR (at doses between 10 to $20 \mathrm{mg} /$ day, more commonly used at that time). By restricting the analysis to the placebo group only, the RADIANT-2 also evaluated the anti-proliferative effect of SSAs. The median duration of treatment was 37 weeks for patients treated with octreotide LAR only group (placebo). The median progression-free survival (PFS) in this group was 11.3 months. These data may support the antiproliferative effects of octreotide acetate LAR demonstrated in the PROMID study.

As a result of these data, the European Neuroendocrine Tumor Society (ENETS) 2012 guidelines stated that the use of SSAs, especially octreotide acetate LAR, is recommended for antiproliferative purposes

\section{Figure 4: The PROMID Trial - Time to Progression and Overall Survival}

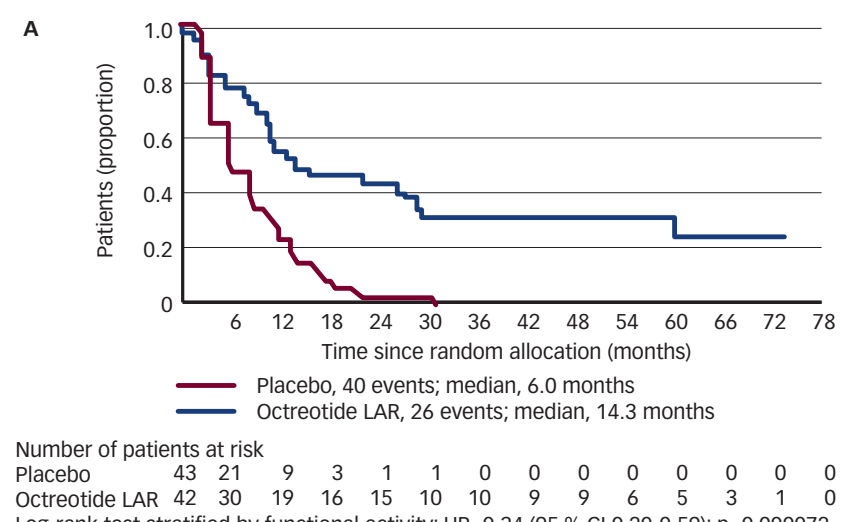

$\begin{array}{llllllllllllll}\text { Octreotide LAR } & 42 & 30 & 19 & 16 & 15 & 10 & 10 & 9 & 9 & 6 & 5 & 3 & 1\end{array}$

Log-rank test stratified by functional activity: $\mathrm{HR}=0.34$ (95 \% Cl 0.20-0.59); $\mathrm{p}=0.000072$

B

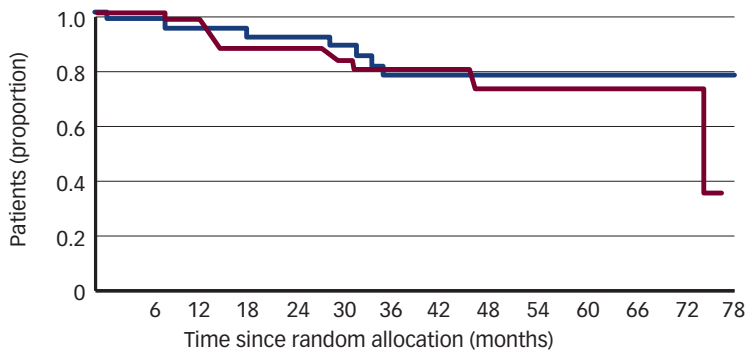

— Placebo, 9 events; median, 73.7 months

Octreotide LAR, 7 events; median, $>77.4$ months

Number of patients at risk

$\begin{array}{lllllllllllllll}\text { Placebo } & 43 & 41 & 39 & 29 & 27 & 25 & 19 & 11 & 11 & 8 & 6 & 4 & 2 & 0\end{array}$

$\begin{array}{lllllllllllllll}\text { Octreotide LAR } & 42 & 39 & 32 & 31 & 29 & 27 & 20 & 16 & 16 & 10 & 9 & 7 & 2 & 0\end{array}$

Log-rank test stratified by functional activity: $\mathrm{HR}=0.81$ ( $95 \% \mathrm{Cl} 0.3-2.18$ ); $\mathrm{p}=0.77$

A. Conservative intent-to-treat analysis of time to progression or tumour-related death B. Intent-to-treat analysis of overall survival. $\mathrm{Cl}=$ confidence interval; $H R=$ hazard ratio, LAR = long-acting release. Source: Rinke et al., 2009.17

in functioning and non-functioning midgut tumours. ${ }^{15}$ The National Comprehensive Cancer Network also recommends octreotide acetate LAR as a treatment option in patients with asymptomatic metastatic GI-NETs in addition to use in symptomatic patients and patients with significant tumour burden, progressive disease and local effects. ${ }^{16}$ Additionally, the recently presented CLARINET study demonstrated that lanreotide had a positive effect on PFS and provides further evidence of the antiproliferative effect of SSAS.

Future studies should establish the efficacy and safety of octreotide LAR in combined treatment regimens. Although higher doses have been used and have been effective when needed to relieve refractory symptoms, ${ }^{9} 30 \mathrm{mg}$ is the approved dose based on clinical trial evidence. ${ }^{17,28}$ Numerous clinical studies have examined the efficacy and safety of octreotide in combination regimens. A randomised study ( $n=109)$ compared subcutaneous octreotide alone or in combination with IFN- $\alpha$. Survival in the combined arm was prolonged but did not achieve statistical significance. Response rates in both arms were less than $6 \% .^{35}$ Another trial with interferon alpha (IFN- $\alpha$ ) failed to reach statistical significance. ${ }^{36}$ The underpowered nature of the studies to date precludes any definitive conclusions regarding the effects of IFN- $\alpha$ on OS. Furthermore, the adverse events (AES) associated with IFN- $\alpha$ have lessened enthusiasm for this combined regime.

Octreotide LAR, in combination with everolimus, has shown reduced disease progression in low- to intermediate-grade metastatic, unresectable carcinoid tumours or islet cell tumours, ${ }^{37}$ advanced pNETS ${ }^{38}$ and lung ${ }^{39}$ and colorectal NETS. ${ }^{40}$ Further analyses of the placebo arm of the RADIANT-2 study may reveal more data on the effect of octreotide in this study population. 


\section{Safety and Tolerability of Octreotide}

The safety profile of octreotide is well established, and both the shortand long-acting formulations are well tolerated in clinical practice and have been associated in improvements in quality of life. ${ }^{41}$ The most frequent AES associated with the use of octreotide LAR include pain at the injection site (10-20\% of patients), mild hyperglycaemia and mild-to-moderate Gl disturbances, such as loose stools, abdominal cramping, nausea and flatulence, which persist in 5-15\% of patients. 17,28,42,43 Octreotide therapy confers a risk of cholelithiasis, which may increase with longer treatment periods. Octreotide-associated biliary tract alterations, such as gallstones, sediment and sludge, have been reported in up to $20 \%$ of patients, but are usually asymptomatic and do not require surgical or pharmacological intervention. ${ }^{44}$ It should be stressed that most studies investigating the safety and tolerability of octreotide have short-term follow up but in clinical practice, the drug is often administered for many years. Long-term AES are less certain and could potentially be underestimated.

\section{Summary and Concluding Remarks}

The incidence of GEP-NETs is increasing dramatically. Over the past 25 years, octreotide has become an essential component in the management of patients with GEP-NETs. Its potent anti-secretory effects and multiple mechanisms of action, combined with its established safety profile, make it a reliable treatment option. Furthermore, clinical data support the antiproliferative effect of octreotide LAR in patients with well-differentiated metastatic midgut NETS. Octreotide LAR may also be considered as treatment option for patients with welldifferentiated metastatic non-midgut NETs, regardless of functional status. These expanded therapeutic indications for octreotide LAR are under investigation in numerous clinical settings.
1. Oberg K, Castellano D, Current knowledge on diagnosis and staging of neuroendocrine tumors, Cancer Metastasis Rev, 2011;30(Suppl. 1):3-7.

2. Kimura W, Kuroda A, Morioka Y, Clinical pathology of endocrine tumors of the pancreas. Analysis of autopsy cases, Dig Dis SCi, 1991;36:933-42.

3. Yao JC, Hassan M, Phan A, et al., One hundred years after 'carcinoid': epidemiology of and prognostic factors for neuroendocrine tumors in 35,825 cases in the United States, Clin Oncol, 2008;26:3063-72.

4. Modlin IM, Oberg K, Chung DC, et al., Gastroenteropancreatic neuroendocrine tumours, Lancet Oncol, 2008:9:61-72.

5. Lal A, Chen $\mathrm{H}$, Treatment of advanced carcinoid tumors, Curr Opin Oncol, 2006;18:9-15.

6. Bauer W, Briner U, Doepfner W, et al., SMS 201-995: a very potent and selective octapeptide analogue of somatostatin with prolonged action, Life SCi, 1982;31:1133-40.

7. Florio T, Molecular mechanisms of the antiproliferative activity of somatostatin receptors (SSTRS) in neuroendocrine tumors, Front Biosci, 2008;13:822-40.

8. Susini C, Buscail L, Rationale for the use of somatostatin analogs as antitumor agents, Ann Oncol, 2006;17:1733-42.

9. Chadha MK, Lombardo J, Mashtare T, et al., High-dose octreotide acetate for management of gastroenteropancreatic neuroendocrine tumors, Anticancer Res, 2009;29:4127-30

10. Theodoropoulou M, Zhang J, Laupheimer S, et al., Octreotide a somatostatin analogue, mediates its antiproliferative action in pituitary tumor cells by altering phosphatidylinositol 3-kinase signaling and inducing Zac1 expression, Cancer Res, 3-kinase signaling

2006;66:1576-82.
11. Grozinsky-Glasberg S, Shimon I, Korbonits M, et al, Somatostatin analogues in the control of neuroendocrine tumours: efficacy and mechanisms, Endocr Relat Cancer 2008;15:701-20.

12. Sandostatin ${ }^{\oplus}$ LAR Depot (octreotide acetate for injectable suspension) prescribing information. Novartis Pharmaceuticals Corporation. East Hanover, New Jersey. Revised 12/2011.

13. Sandostatin ${ }^{\circledast}$ LAR (octreotide). Summary of product characteristics. Novartis Pharmaceuticals UK Limited. Surrey, United Kingdom. Revised 04/2013.

14. Novartis pharmaceuticals. Avaialble at: http://www.novartis. $\mathrm{com} /$ downloads/newsroom/corporate-fact-sheet/2a

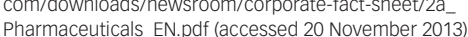

15. Pavel M. Baudin E_Courvelard A, et al, ENETS Consensus Guidelines for the management of patients with liver and other
and distant metastases from neuroendocrine neoplasms of foregut, midgut, hindgut, and unknown primary, Neuroendocrinology, 2012;95:157-76.

16. NCCN, National Comprehensive Cancer Network. NCCN Clinical Practice Guidelines in Oncology ${ }^{\mathrm{TM}}$ Neuroendocrine Tumors. National Comprehensive Cancer Network Web site. Available at: http://www.nccn.org/professionals/physician_gls/ pdf/neuroendocrine.pdf. (accessed 20 November 2013).

17. Rinke A, Muller HH, Schade-Brittinger $\mathrm{C}$, et al., Placebocontrolled, double-blind, prospective, randomized study on the effect of octreotide LAR in the control of tumor growth in patients with metastatic neuro of umor growth in patients with metastatic neuroendocrine midgut
tumors: a report from the PROMID Study Group, 1 Clin Oncol, tumors: a report fron

18. Modlin IM, Latich I, Kidd M, et al., Therapeutic options for gastrointestinal carcinoids, Clin Gastroenterol Hepatol, 2006;4:526-47.
19. Oberg K, Kvols L, Caplin M, et al., Consensus report on the use of somatostatin analogs for the management of neuroendocrine tumors of the gastroenteropancreatic system, Ann Oncol, 2004;15:966-73.

20. Tomassetti P, Migliori M, Corinaldesi R, et al., Treatment of gastroenteropancreatic neuroendocrine tumours with octreotide LAR, Aliment Pharmacol Ther, 2000:14:557-60

21. Warner RR, Mani S, Profeta J, et al., Octreotide treatment of carcinoid hypertensive crisis, Mt sinai J Med, 1994;61:349-55.

22. Anthony LB, Martin W, Delbeke D, et al., Somatostatin recepto imaging: predictive and prognostic considerations, Digestion, 1996:57(Suppl. 1):50-53.

23. Astruc $B$, Marbach $P$, Bouterfa $H$, et al., Long-acting octreotide and prolonged-release lanreotide formulations have different pharmacokinetic profiles, I Clin Pharmacol, 2005;45:836-44. 24. Chen T, Miller TF, Prasad P, et al., Pharmacokinetics, pharmacodynamics, and safety of microencapsulated octreotide acetate in healthy subjects, I Clin Pharmacol, 2000;40:475-81.

25. Anthony LB, Kang T, Shyr Y, Malignant carcinoid syndrome: Survival in the octreotide LAR era, J Clin Oncol, 2005 ASCO Annual Meeting Proceedings, 2005:23(16S):abstract no. 4084.

26. Arnold R, Wittenberg, M Rinke, A et al., Placebo controlled, doul , Wittenter of octreotide LAR in the control of tumor growth in patients of octreotide LAR in the control of tumor growth in patien with metastatic neuroendocrine midgut tumors (PROMID):
Results on long term survival, J Clin Oncol, 2013;(Suppl. 31 abstr 4030).

27. Arnold RM, H; Schade-Brittinger, $\mathrm{C}$ et al, Placebo-controlled double-blind, prospective, randomized study of the effect of octreotide LAR in the control of tumor growth in patients with metastatic neuroendocrine midgut tumors: A report from the PROMID study group, presented at the 2009 ASCO G Symposium, 15-17 January 2009, San Francisco, CA. Abstract no 121

28. Pavel ME, Hainsworth JD, Baudin E, et al., Everolimus plus octreotide long-acting repeatable for the treatment of advanced neuroendocrine tumours associated with carcinoid syndrome (RADIANT-2): a randomised, placebo-controlled, phase 3 study, Lancet, 2011:378:2005-12.

29. Panzuto F, Di Fonzo M, lannicelli E, et al., Long-term clinical outcome of somatostatin analogues for treatment of progressive, metastatic, well-differentiated entero-pancreatic endocrine carcinoma, Ann Oncol, 2006;17:461-6.

endocrine carcinoma, Ann Oncol, 2006;17:461-6.
30. Bajetta E, Catena L, Procopio G, et al., IS the new WHO

30. Bajetta $E$, Catena $L$, Procopio $G$, et al., Is the new WHO
classification of neuroendocrine tumours useful for selecting classification of neuroendocrine tumours useful for selecting

31. Pavel M, Heuck F, Plockinger U, et al., Prospective randomized trial: biotherapy versus chemotherapy in malignant nonfunctional neuroendocrine tumors of the pancreas and bronchial tract (ENET-1). Presented at: ASCO GI Cancers Symposium. Orlando, FL, US, January 25-27, 2008 (Abstract 202).

32. Shojamanesh H, Gibril F, Louie A, et al., Prospective study of the antitumor efficacy of long-term octreotide treatment in patients with progressive metastatic gastrinoma, Cancer 2002:94:331-43.

33. Weckbecker $\mathrm{G}$, Raulf $\mathrm{F}$, Tolcsvai $\mathrm{L}$, et al., Potentiation of the anti-proliferative effects of anti-cancer drugs by octreotide in vitro and in vivo, Digestion, 1996:57(Suppl. 1):22-8.

34. Caplin M, Phan A, Liyanage N, The CLARINET study: Assessing the effect of lanreotide autogel on tumor progression-free survival in patients with nonfunctioning gastroenteropancreatic neuroendocrine tumors, Eur I Cancer, 2013;49 (Suppl. 3):Abstract E17-7103.

35. Arnold R, Rinke A, Klose KJ, et al., Octreotide versus octreotide plus interferon-alpha in endocrine gastroenteropancreatic tumors: a randomized trial, Clin Gastroenterol Hepatol 2005;3:761-71

36. Faiss S, Scherubl H, Riecken EO, et al., Interferon-alpha versus somatostatin or the combination of both in metastatic neuroendocrine gut and pancreatic tumours, Digestion, 1996;57(Suppl. 1):84-5.

37. Yao JC, Phan AT, Chang DZ, et al., Efficacy of RAD001 (everolimus) and octreotide LAR in advanced low- to intermediate-grade neuroendocrine tumors: results of a phase intermediate-grade neuroendocrine tumor

38. Yao JC, Lombard-Bohas C, Baudin E, et al., Daily oral everolimus activity in patients with metastatic pancreatic neuroendocrine tumors after failure of cytotoxic chemotherapy: a phase II trial, J Clin Oncol, 2010;28:69-76.

39. Fazio N, Granberg D, Grossman A, et al., Everolimus plus octreotide long-acting repeatable in patients with advanced lung neuroendocrine tumors: analysis of the phase 3 , randomized, placebo-controlled RADIANT-2 study, Chest, 2013;143:955-62.

40. Castellano D, Bajetta E, Panneerselvam A, et al., Everolimus plus octreotide long-acting repeatable in patients with colorectal neuroendocrine tumors: a subgroup analysis of the phase III RADIANT-2 study, Oncologist, 2013;18:46-53.

41. Pistevou-Gombaki $K$, Eleftheriadis N, Plataniotis $G A$, et al Octreotide for palliative treatment of hepatic metastases from non-neuroendocrine primary tumours: evaluation of quality of life using the EORTC QLQ-C30 questionnaire, Palliat Med, 2003; 17:257-62.

42. Garland J, Buscombe JR, Bouvier C, et al., Sandostatin LAR (long-acting octreotide acetate) for malignant carcinoid syndrome: a 3-year experience, Aliment Pharmacol Ther 2003;17:437-44.

43. O'Toole D, Ducreux M, Bommelaer G, et al., Treatment of carcinoid syndrome: a prospective crossover evaluation of lanreotide versus octreotide in terms of efficacy, patient acceptability, and tolerance, Cancer, 2000;88:770-76.

44. Redfern JS, Fortuner WJ, 2nd, Octreotide-associated biliary tract dysfunction and gallstone formation: pathophysiology and
dy management, Am I Gastroenterol, 1995:90:1042-52.

45. Saltz L, Trochanowski B, Buckley M, et al., Octreotide as an antineoplastic agent in the treatment of functional and nonfunctional neuroendocrine tumors, Cancer, 1993;72:244-8.

6. Arnold R, Trautmann ME, Creutzfeldt W, et al., Somatostatin analogue octreotide and inhibition of tumour growth in metastatic endocrine gastroenteropancreatic tumours, Gut, 1996;38:430-38.

47. di Bartolomeo M, Bajetta E, Buzzoni R, et al., Clinical efficacy of octreotide in the treatment of metastatic neuroendocrine tumors. A study by the Italian Trials in Medical Oncology Group, Cancer, 1996;77:402-8.

48. Aparicio T, Ducreux M, Baudin E, et al., Antitumour activity of somatostatin analogues in progressive metastatic neuroendocrine tumours, Eur J Cancer, 2001:37:1014-19.

49. Butturini $G$, Bettini R, Missiaglia E, et al., Predictive factors of efficacy of the somatostatin analogue octreotide as first line therapy for advanced pancreatic endocrine carcinoma, Endocr Relat Cancer, 2006;13:1213-21. 